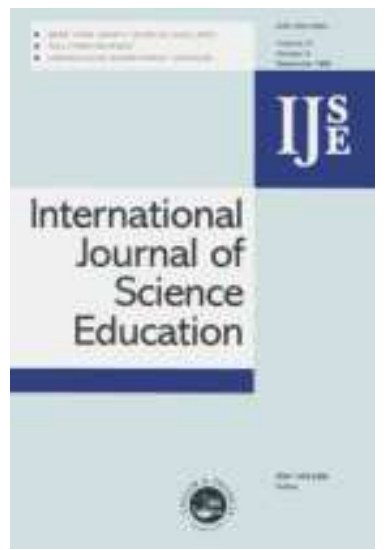

\title{
An exploration of attitudes towards modern biotechnology; A study among Dutch secondary school students
}

\begin{tabular}{|r|l|}
\hline Journal: & International Journal of Science Education \\
\hline Manuscript ID: & TSED-2006-0091.R2 \\
\hline Manuscript Type: & Research Paper \\
\hline Keywords: & quantitative research, secondary school, survey, science education \\
\hline Keywords (user): & attitudes, cluster analysis, modern biotechnology \\
\hline
\end{tabular}

\section{S ScholaroNE" \\ Manuscript Central}




\title{
An exploration of attitudes towards modern biotechnology; A study among Dutch secondary school students
}

\begin{abstract}
Modern biotechnology will have a large impact on society and requires informed decision-making and critical attitudes toward biotechnology among the public. This study aims to explore these attitudes in secondary education.

For this purpose, a questionnaire was constructed according to the general tripartite theory of attitudes. 574 Dutch secondary school students completed the questionnaire. Based on principal component analyses, several distinct and independent cognitive, affective, and behavioural factors were found, demonstrating that attitudes towards biotechnology are a multi-component concept. In a cluster analysis on these factors, we found four interpretable clusters representing different groups of students. The four groups are labelled as 'confident supporter' (22\%), 'not sure' (42\%), 'concerned sceptic' $(18 \%)$ and 'not for me' $(17 \%)$. These results indicate that there is a diverse appraisal of modern biotechnology amongst secondary school students. Suggestions for educational interventions are made.
\end{abstract}




\section{Introduction}

Genomics, the new term for large-scale scientific research on heredity and genes, and its associated technologies (modern biotechnology ${ }^{1}$ ) are set to become one of the most important scientific and technological revolutions of the 21st century (Kirkpatrick, Orvis, \& Pittendrigh, 2002). As such, it is important that the general public understands the main concepts of modern biotechnology. People will need such knowledge in their careers and in their daily lives as members of society to make personal and social choices about issues related to science and technology. In short, it is important that the public becomes more scientific literate in this respect. Our starting point is that science education occupies a central role in the promotion of scientific literacy (Bingle \& Gaskell, 1994; Driver, Leach, Millar, \& Scott, 1996; Zeidler \& Keefer, 2003; Sadler \& Zeidler, 2004). When developing an educational strategy, or programme, obviously one must know its 'audience' and consider what understanding modern biotechnology means, and how students arrive at personal and social choices. What kind of arguments do students use in relation to knowledge they may or may not have on the subject? In other words, what different attitudes towards modern biotechnology can be distinguished?

In the next section, we will describe the results of published literature on attitudes of school students towards modern biotechnology within the last 10 years.

\section{Former research}

A small number of studies have examined understanding of secondary school students of, and attitudes towards, modern biotechnology (Dawson \& Schibeci, 2003b). These studies

\footnotetext{
${ }^{1}$ Biotechnology is a term used to encompass a vast range of techniques for modifying life forms for research (e.g., medical, environmental, agricultural) and commercial uses.
} 
have investigated students' attitudes towards school science in general (see the review of (Osborne, Simon, \& Collins, 2003) or attitudes towards selected biotechnological applications such as genetic engineering of plants (Gunter, Kinderlerer, \& Beyleveld, 1998) or attitudes of students towards using genetically engineered animals in medical research (Hill, Stannistreet, O’Sullivan, \& Boyes, 1999). However, most of these studies focused on student's knowledge and understanding of biotechnology more than on their attitudes.

The number of studies on attitudes towards biotechnology among the general public seems quite substantial, although many of these draw from the so-called Eurobarometer. This concerns one of the main sources of information on attitudes towards biotechnology (European Commission, 2006). It is an extensive survey on society, science and technology in European countries conducted several times in the past decade. The Eurobarometer includes a number of questions on content knowledge and views among the public regarding different applications of biotechnology. Other studies generally focused on one specific application of biotechnology such as genetically modified foods (GM-foods)(Verdurme \& Viaene, 2003) and medical applications and cloning (Balas \& Hariharan, 1998). Below, the main studies on attitude towards biotechnology conducted in groups of adults as well as secondary school students will be described. Our review of these studies includes a description of the results in relation to the particular conceptualisation of attitude.

Pardo, Midden and Miller (2002) have described the profile of Europeans attitudes towards biotech applications based on the results of particular questions of the Eurobarometer of 1996. In their article, attitudes were defined as an evaluation of an 
object based on a cognitive component (information and knowledge about the properties of the object) and an evaluative component (affect and feelings of approval or disapproval toward the object). Pardo et al. expected the public to hold general views on the one hand, as well as more differentiated views regarding specific biotech applications on the other. This means that attitudes towards biotechnology are expected to be fragmentary, especially because it concerns such a complex and developing subject. The Eurobarometer included questions about six specific applications of biotechnology (in the medical as well as food production area), and examined to what extent the respondents finds these applications useful, risky, moral acceptable, and whether or not the person would encourage each of the applications. First of all, the results showed that, while some progress in terms of basic scientific knowledge have been made since the Eurobarometer of 1996, the knowledge - and information gap between science and society still exists. Furthermore, attitudes (comprising the perception of usefulness, risk, moral acceptability and encouragement) were somewhat more positive when medical applications are at stake (research and transplants), compared to foods and agricultural applications.

Pardo et al. continued their article by conducting a structural analysis that aimed to explain the perceived benefits and risks. A positive perception of the benefits was predicted by a general technological optimism, a belief in the promise of biotech and being part of an informed public (groups were divided based on a knowledge test, p. 11, note 2). The same model, however, failed to predict the perception of risk, suggesting that other factors in the structural model were needed to explain underlying reasons for the public to perceive biotechnology as a risk. 
Dawson and Schibeci (2003a) have conducted a study among 1116 secondary school students from different Western Australian schools on the understanding of recent advances in modern biotechnology. For this research, a written survey was used to determine their understanding of, and attitudes towards, recent advances in modern biotechnology, such as genetic engineering, cloning and GM-foods.

In this study, attitudes were defined in terms of acceptability of biotechnological procedures. Students indicated whether they thought different procedures were acceptable and clarified their choice. The survey included six questions related to understanding and acceptance of biotechnological applications and procedures.

Approximately one third of the students turned out to have little or no understanding of biotechnology and one third was unable to give a single example of biotechnology.

However, there was considerable variation in the understanding of students.

The results on attitude towards biotechnology in a successive study (Dawson \& Schibeci, 2003b) showed that the students hold a wide range of beliefs about what is an acceptable use of biotechnology. The students' responses divided approximately into four groups depending on whether they approved of the use of micro-organisms only, microorganisms and plants, micro-organisms, plants and animals, or all living organisms. Acceptance of the use of organisms in biotechnology decreases from micro-organisms (>90\% approval) to plants $(71-82 \%)$ to humans $(42-45 \%)$ and animals $(34-40 \%)$. Clarification of their statements for acceptance or rejection was rather negative. Arguments such as 'the procedure is wrong', 'unnatural', or 'unethical' were given. Reasons for acceptance were that procedures will benefit humanity or 'if it can be done then it should be done'. 
Gunter et al. examined the understanding and opinion towards biotechnology of 48 teenagers, with special reference to food production. This study was part of a large project designed to investigate public awareness and perception of biotechnology. The results showed that despite these young peoples' poor understanding of biological sciences, they seemed less reluctant towards GM-foods than did adult-respondents. Overall, teenagers considered genetic engineering of plants to be more acceptable than genetic engineering of food crops and animals. Their reasons for opposing genetic engineering of animals was that it is 'unnatural', 'dangerous', 'shouldn't be done' and 'unethical'.

Similar reasons were reported by Hill et al. (1999) who examined the attitudes of 778 students aged 11 - 18 years about using genetically engineered animals in medical research. $42 \%$ of the sample felt it should not be allowed, because it was cruel (47\%), or unnatural $(53 \%)$.

Hill et al. also found that biology students were less likely to be neutral and more likely to be positive about genetically engineered foods than other students. While these positive attitudes may be the result of a greater understanding of biotechnology, it could also be argued that the students who have chosen to study biology have a more positive attitude to science than other students.

From the angle of non-persuasive communication, Verdurne and Viaene (2003) conducted a study on consumer beliefs and attitudes towards GM-foods. Their attitude model included risk and benefit perceptions, which were determined by general attitudes and knowledge about GM-foods. In their interviews with 400 Belgian consumers, they asked about the risk and benefits, awareness and knowledge, attitudes towards science, 
trust in the government, and beliefs, attitudes and purchase intentions regarding GMfoods. They observed three general factors based on the risk and benefit items: a general health risk factor, a benefit factor and an environmental risk factor. These three factors clustered into four consumer segments: 'the half-hearted' (34\%), 'the green opponents' (16\%), 'the balancers' (27\%) and 'the enthusiasts' (24\%). Several items that combined into one general scale with a high reliability, measured attitudes. Knowledge was measured using the Eurobarometer knowledge items. The results showed that higher levels of knowledge do not necessarily imply greater acceptance of GM-foods. In summary, looking at these studies suggests that attitudes towards biotechnology do not yet constitute a coherent research area. Some studies defined attitudes in terms of benefits and risks, some defined attitudes in terms of acceptability, and others in terms of a general evaluation. Most studies described a link between understanding or content knowledge and attitudes, but few studies actually investigated this link. Pardo and Calvo (2002) criticised the theoretical underpinning of attitudes towards science (and biotechnology) as measured in the Eurobarometer. They stated that little to no attention was paid to the content of attitudinal items and argued that this leads to conceptual and metrical weakness of scales. The consequence is that empirical support for some published results is very limited (see for an in-depth discussion; (Miller, 1998; Pardo \& Calvo, 2002, 2004). This seems to be a recurrent issue with research on attitudes. It is not only a complex construct, but a person's attitude seems also incomplete and in a state of evolution, especially in case of extremely complex subjects such as biotechnology (Campbell, Converse, Miller, \& Stokes, 1976; Pardo, Midden, \& Miller, 2002). 
The present study uses the theoretical tripartite model of attitudes (Katz \& Stotland, 1959; Rosenberg \& Hovland, 1960) as a starting point. This model encompasses three basic attitude components: an affective, a cognitive, and a behavioural component. By choosing this theoretical and empirical strongly underpinned conceptualisation of attitudes, we intend to accommodate the critique of Pardo regarding the generally weak conceptualisation of attitudes towards science. Furthermore, each of the three components is considered as a multi-dimensional component: our conceptualisation of attitudes attempts to uncover different sets of affective, cognitive and behavioural reactions towards modern biotechnology. By doing this, the present study contributes to research on attitudes towards modern biotechnology by exploring the concept of attitudes in detail.

\section{The attitude model in the present study}

In general, an attitude can be described as a summary evaluation depicting favourable or unfavourable feelings towards a specific or psychological object (Eagly \& Chaiken, 1993; Weinburgh \& Engelhard, 1994; Ajzen \& Fishbein, 2000; Zacharia, 2003). In the present study the object is modern biotechnology, in specific the associated technologies of genomics. According to the tripartite theory of attitudes, attitudinal responses can be classified into three general components; an affective, a cognitive, and a behavioural component (Katz \& Stotland, 1959; Rosenberg \& Hovland, 1960; Breckler, 1984; Eagly \& Chaiken, 1993). The cognitive as well as the affective component influence evaluations which in turn affects behavioural intentions (Tesser \& Shaffer, 1990; Heijs, Midden, \& Drabbe, 1993; Ajzen, 2001). In the cognitive component, the evaluation of 
modern biotechnology follows from beliefs, thoughts and knowledge of the object. The affective component of attitudes reflects how students feel about genomics, for instance anxieties and fears about this contemporary technology. Furthermore, attitude is one of the important determinants of intentions and behaviour, for example consumption or protest (theory of planned behaviour) (Ajzen \& Fishbein, 2000; Armitage \& Conner, 2001; Zacharia, 2003).

\section{Research questions}

The concept of attitude includes levels of knowledge as well as cognitive and affective evaluations and behavioural intentions. In the following quantitative study, each of the components of the tripartite attitude model will be explored and related to each other. Therefore, the following three research questions can be formulated:

1. Which kind of cognitive, affective evaluations and behavioural intentions can be observed?

2. How do these attitude components interrelate?

3. Can different attitude patterns of secondary school students be distinguished? 


\section{Method}

The main aim of this study is the exploration of secondary school students' attitudes towards modern biotechnology in more detail. For this purpose an instrument (questionnaire) was designed which measures the various attitude components in relation to content knowledge and different areas of modern biotechnology.

\section{Participants}

Based on a list of all Dutch schools in four large cities in the western part of the Netherlands, teachers were invited to participate with their students. A total of 47 schools were approached, of which thirteen consented to participate with one or more of their classes of sixteen-year-old students.

In the Netherlands, the secondary education system for pupils aged between twelve and eighteen years is divided into three main levels: secondary vocational education (VMBO, 12-16 years), general secondary education (HAVO, 12-17 years), and pre-university secondary education (VWO, 12-18 years). A total sample of 634 secondary school students of all three main school levels took part in the study.

Students were excluded from subsequent analysis if they completed less than $33.3 \%$ of the questionnaire or showed a 'suspicious' answer-pattern, e.g., all questions were responded to in identical fashion, or included contradictions. This resulted in a dataset of 574 respondents, 147 from $\mathrm{VMBO}^{2}$ (25.6\%), 147 from HAVO (25.6\%), 280 from VWO (48.8\%), with 262 males (45.6\%) and 312 females (54.4\%). Focus was on sixteen-yearold students $($ mean $=15.8$ year, $\mathrm{SD}=0.66)$.

\footnotetext{
${ }^{2}$ The group of students in the pre-vocational tracks are underrepresented (in Dutch educational system nearly $60 \%$ of secondary school students are in this track), and also the coverage of the region is not equally spread.
} 


\section{Design of instrument}

The questionnaire was designed based on two sources: a variety of existing surveys and a small-scale qualitative research study.

A literature search regarding possible surveys resulted in a number of instruments of which items could be used for the purpose of the present study, including surveys on attitude towards science. The most important of these are the Eurobarometer (European Commission, 2001), the instrument of Heijs (Heijs et al., 1993) and the International Bioethics Survey Questionnaire. One or more items or ideas have been taken from other surveys ${ }^{3}$.

The qualitative study consisted of six group discussions with four different sixteen-yearold students (from all three main educational levels) and thirteen in-depth interviews with researchers in the field of genomics.

In the group discussions, the students were questioned about their knowledge and understanding of biology, genetics and modern biotechnology, their feelings towards several applications of biotechnology, and behavioural intentions towards biotechnology. The students were also asked to elaborate their perception of risk associated with biotechnology, their ethics and beliefs, and their own experience and interest.

Discussions with the students were tape-recorded and the responses were transcribed verbatim and analysed afterwards. Each interview lasted approximately fifty minutes. The qualitative study among students served two goals. First of all, the open-ended questions uncovered the cognitive and affective base of attitude in detail. This is an important condition to arrive at construct validity of the instrument.

\footnotetext{
3 (Human Genetics Commission, 2000; Centre for Consumer \& Biotechnology, 2002; Princeton Survey Research Associates, 2002).
} 
Secondly, the interviews with students were also used to adapt the used language in the existing instruments. This adaptation was needed because these instruments generally aim at adults.

The interviews with genomics researchers resulted in an overview of modern biotechnology. In accordance with existing instruments, the objects have been classified as follows: agriculture (plants, food industry), livestock (animals, animal experiments, food industry), medical science (medicines, diagnostics, treatments), industry (microorganisms) and legislation.

\section{The instrument}

The first section of the instrument was designed to obtain (socio-) demographic information about the students. The second and third part of the instruments includes four categories of items: knowledge items, cognitive evaluation items (beliefs), affective evaluation items, and behavioural intention items.

\section{Knowledge items}

In the second section, the cognitive component of attitude towards biotechnology was measured through 47 true-false items (bivariate items). In this instrument, the items cover relevant school-subjects in the field of biotechnology: 'biology and genetics' and 'technology and science'. Students should (or could) have learnt about these subjects in school or from popular science programmes or magazines. Some items cover the existing misconceptions about modern biotechnologies. Incorrect answers on these items reflect not only lack of scientific knowledge (textbook knowledge) but also a tendency to 
associate biotechnology with several existing inaccuracies (European Commission, 2001).

\section{Cognitive and affective evaluation items}

The third section asked students about their cognitive and affective evaluation about biotechnology. The affective evaluation is measured by 28 Likert-type items, represented by questions concerning negative and positive feelings and emotions towards different aspects of modern biotechnology. Thirteen items on cognitive evaluation tried to capture beliefs, expectancies, and perceptions of modern biotechnology.

\section{Behavioural intention items}

The third section also measured the behavioural intentions (20 Likert-type items). Since secondary school students usually have not encountered many contexts in which they had to act or make a decision regarding biotech issues, we decided to measure behavioural intentions as a proxy for actual behaviour. These intentions were examined by outlining situations in which one will or will not act (protest against genetic modification of crop), buy (jeans made of genetically modified cotton) or use (genetic screening).

\footnotetext{
The items from the third section were measured by five ordinal categories ranging from 'strongly disagree' to 'strongly agree' (Becker \& Maunsaiyat, 2002). Together, the second and third sections of the instrument measured the basic components of attitude.
} 


\section{Fourth section}

The questionnaire continues with explanatory factors: students' ethical opinions (number of items is 45), their interest in biotech $(n=10)$, source of information and school factors $(n=9)$, benefits and risk of biotechnology $(n=35)$, own judgement of opinion $(n=13)$ and trust in biotechnology and different institutes. In a subsequent article, the results of these explanatory factors will be described, together with the relationships between background variables and attitude.

\section{Administration}

In the period from February through April 2004, teachers administered an on-line version of the questionnaire during a regular class. In this way, the questionnaire could be answered immediately, and the response rate of the students was $100 \%$. Either the teacher or the researcher gave the students instructions.

\section{Analyses}

Data were analysed by means of the Statistical Package for Social Sciences software, version 12.0.1. (SPSS). The analyses were conducted in two steps: 1) scaling of attitudinal factors and 2) exploring subgroups of students sharing similar 'attitudinal values'.

In the first step of scaling, factor analyses (principal component analyses with varimax rotation) and reliability analyses are used to arrive at underlying structures of the three main components of attitude. 
Subsequently, the items loading high on the 'interpretable' factors are analysed in reliability analysis. To arrive at scales with sufficient reliability, items with low item-total correlation were removed from the scale and excluded from further analysis. This was done only in those instances where the content of the scale was not jeopardized.

In the second step, K-means cluster analysis using Euclidean distance was performed on the attitudinal scales. K-means cluster analysis is a statistical method for finding subgroups of individuals who share similar 'values' on a set of variables, builds group clusters by finding cluster centres on values of variables and assigning cases to the cluster that produce the best-fit model.

\section{Results}

First, we present the results of the factor analyses.

\section{Content knowledge}

The item pool consisted of 47 true-false statements intended to cover, as broadly and as relevantly possible, 'school-topics' of biotechnology and genetics. The mean score for the whole sample was $34.02(\mathrm{SD}=5.33)$.

We constructed the scales based on a priori classification of the items (according to the contents of the Dutch secondary biology education), namely 1) biology and genetics and 2) biotechnology and its applications.

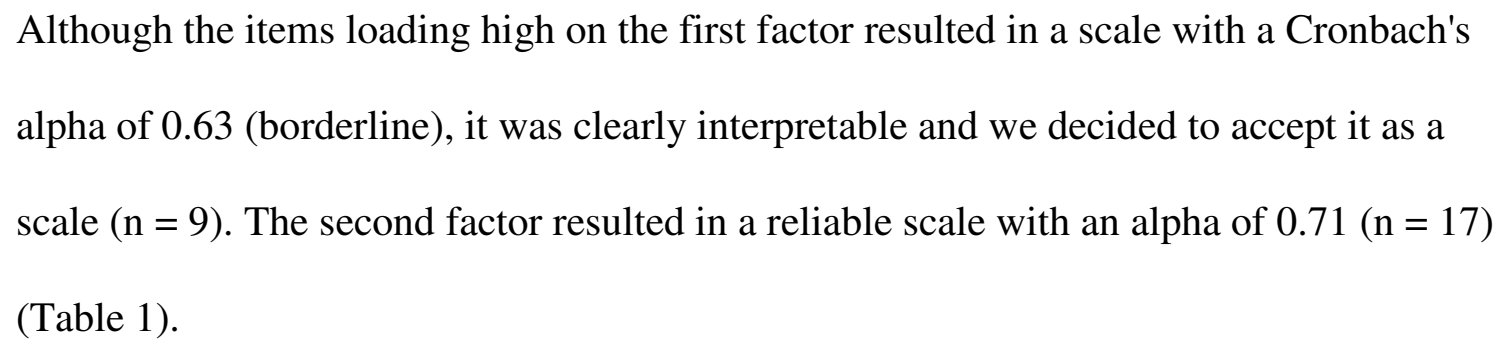




\section{Cognitive evaluation, beliefs.}

The questionnaire included 11 items that aimed to evaluate attributes of genomics. An exploratory factor analysis was conducted on the responses to the 11-evaluation items. Principal components analysis with varimax rotation (PCA: VR) was initially performed without specifying the number of factors to extract, since there was no expected factor structure. Factor analysis showed that the best result was a one-factor solution with five items on beliefs about biotech (explained variance is $26.1 \%$ ). Reliability analysis confirmed this finding with an alpha of 0.70 (Table 1). Apparently, students group all 'cognitive' attributes on one dimension. They are either positive or negative about the different genomics attributes.

\section{Affective evaluation}

Also on the responses to 29-affect items, an exploratory factor analysis was conducted, without specifying the number of factors to extract. A solution with three factors (in total 27 items) turned out to be interpretable. The three factors explained $38.4 \%$ of the variance. The first factor indicated a basic emotional reaction to biotechnology, such as being scared or excited. The second factor indicated feelings of biotechnology as an unavoidable process ('it is going to happen anyway'). The third factor indicated a worried stance, or a feeling of unease regarding biotech developments.

A reliability analysis confirmed this finding. The items showing high factor loadings were included in reliability analyses, which resulted in three reliable scales as shown in Table 1. 


\section{Behavioural intentions}

As mentioned before, the decision was made to incorporate questions regarding students' behavioural intentions only. A total of 20 items was included, and three factors, which explained $58.6 \%$ of variance, were extracted. The first interpretable factor $(\alpha=0.78)$ covered intentions of consuming when there is a personal benefit to gain, for instance when genetically modified (GM) products are cheaper or contain less fat. The second factor included medical intentions, such as undergoing genetic tests, and resulted in a reliable scale of $\alpha=0.74$. The third factor also included consuming intention, but under critical or environmental conditions (e.g. environmentally friendlier). This factor resulted in a scale with a Cronbach's alpha of 0.74 (Table 1)

[Insert table 1 about here]

\section{Clustering of students}

Finally, the whole dataset was subjected to a K-means cluster analysis using Euclidean distance. In this step, we investigated whether subgroups could be identified within the whole group of students. Cluster analysis was used to examine these subgroups. Because of the exploratory nature of these analyses, different numbers of clusters were analysed. An analysis with four clusters led to interpretable and interesting groups with sufficient numbers of students. Figure 1 portrays the factor scores in each of the four clusters. [Insert Figure 1 about here] 


\section{Confident supporter (cluster 1)}

Positive, pro-biotechnology and well educated in science, the 'confident supporter' (130 students, $22.6 \%$ of the respondents) seems to welcome biotechnology in their daily lives. Not only do they hold great expectations for the future, they are enthusiastic and have no worries. They tend to be confident about their future intentions of becoming a consumer of 'biotech- products', from eating genetic modified foods to taking genetic tests during pregnancy (Figure 1).

\section{Not Sure (cluster 2)}

This group of 239 students (41.6\%) forms the largest group of students. Their views tend to be quite indistinct: they are neither 'anti-biotechnology' nor 'pro-biotechnology'. The students in the 'not sure'-group have a good knowledge base and hold positive beliefs about biotechnology but are sceptical when it comes to their 'gut-feelings' (basicemotions). There is also quite some concern about biotechnological developments. However, their negative affection, does not stop them from having intentions towards consuming biotech products, especially not if critical or environmental conditions are met. They also seem to appreciate its applications in the medical world (Figure 1).

\section{Concerned sceptic (cluster 3)}

This relatively well-informed group of 105 students (18.3\%) tends to be very sceptical and concerned about biotechnology. They hold sceptical believes towards biotechnology and seem to be scared and concerned of what modern biotechnology will bring. They fear 
the impact on nature and do not see it as a 'natural' evolvement of the current society. The 'concerned sceptics' have no intention of having anything to do with it now or in the future, especially not in the medical field (Figure 1).

\section{Not for Me (cluster 4)}

This group consists out of 100 students $(17.4 \%$ of the total), and is thereby the smallest group. They are very negative when it comes to biotechnology. They hold very little knowledge about the subject, and their beliefs about biotechnology are very negative. This group of students is less pronounced in their affective reactions. On the other hand, they are very explicit in their behavioural intentions. This 'not for me'-group shows no intentions of ever buying, eating or using anything made from or with modern biotechnology. Only the intention towards the medical field is a little less negative (Figure 1).

\section{Conclusions}

In the present study, the tripartite attitude model was used to explore the concept of attitude towards biotechnology in all its features. In this section, the results will be summarised and compared to former research. Some conclusions will be drawn and the major implications for further research will be presented.

The results show that attitude towards biotechnology is a multi-component concept of various cognitive, affective, and behavioural features. Different types of affective and cognitive evaluations, two different types of content knowledge and three different types of behavioural intentions interact and result in a specific set of four attitude patterns. 
The cognitive component consists of a combination of content knowledge and a cognitive evaluation. The results confirm two different types of knowledge on modern biotechnology. The first type concerns content knowledge on biology and genetics, referring to the basic concepts in this discipline. The second type concerns knowledge and understanding of biotechnology applications. Cognitive evaluation refers to beliefs, expectancies, and perceptions related to modern biotechnology.

Except for the 'not for me'-group of students the respondents in this study show reasonable to very good content knowledge. This is quite different from the most common findings in content knowledge towards biotechnology, which imply limited understanding of concepts and implications of modern biotechnology (Osborne et al., 2003; Dawson \& Schibeci, 2003a). It is possible our study confirms the observed progress in terms of basic scientific knowledge since the Eurobarometer of 1996 (Pardo \& Calvo, 2002). On the other hand, the cognitive evaluation (beliefs and expectancies) of biotechnology seems rather negative. Especially the 'concerned sceptics' and the 'not for me' groups evaluate the attributes of biotechnology in a negative sense. The confident supporters, with the highest level of content knowledge are also most positive about the attributes of biotechnology. However, this link between content knowledge and cognitive evaluation only emerges in this group of supporters. In the other groups, content knowledge does not seem to relate to cognitive evaluation. This is shown for example by the fact that the 'not sure' group and the concerned sceptics do not differ in terms of their knowledge, but they do differ in terms of their cognitive evaluation. These finding shows the complex nature of the relationship between content knowledge and attitude towards biotechnology. Although in general one may conclude that more content knowledge is 
related to more positive cognitive evaluations, it also depends on other aspects of attitude patterns such as affective evaluation and behavioural intentions.

In the affective component, three types of evaluations emerge. The first evaluation can be described as a basic emotional reaction, the second reaction expresses feelings of unavoidability and the third revolves around worries. Students with clear positive basic emotional reactions can be found in the group of 'confident supporters'. The 'concerned sceptics' on the other hand seem to disagree with the stance of 'it is going to happen anyway' combined with high level of concern and unease regarding biotechnology. The remaining two clusters ('not sure' and 'not for me') are less pronounced in their affective evaluations of biotechnology. As described in the introduction, other research on the affective component of attitude often describes attitude in terms of a single dimension: individuals either oppose or favour biotechnology. Our study has clearly shown that the way people feel about biotechnology is a more complex issue.

The behavioural component is indicated by three types of intentions: 1) an intention to consume because it serves one's own interests, 2) an intention to co-operate if it serves medical purposes, and 3) an intention to consume if certain conditions are met, for example, environmental issues. All groups seem to have different kinds or combinations of intentions. For the 'confident supporter'-group the dominant intention is to consume when it is in one owns interests. For the 'not sure'-group critical conditions seem most important for deciding whether or not to become involved with applications of biotechnology.

Both the 'not for me'-group and the group of 'concerned sceptics' do not seem likely to engage with biotechnology at all. A difference between the two groups is that the 
concerned sceptics show no intentions to make use of medical applications, whereas the 'not for me' group seems less reluctant to, for example, take a genetic test when pregnant. The results of the Eurobarometer suggest that most European adults are supportive of biomedical use of biotech. This is only in part confirmed by our results: the confident supporters do seem to intend to engage with biomedical applications, but the remaining groups are more reluctant.

In summary, the findings in our study confirm what is frequently assumed and emphasised in studies on attitudes towards biotechnology (or science in general), namely that the more one knows about the subject, the more positive one's feelings and the more positive the behavioural intentions. This relationship between the three attitudinal components is observed in the comparison of the 'confident supporters' versus the 'not for me'-group. Nevertheless, this study also shows that in the largest group of students ('not sure' and 'concerned sceptics'), a different pattern of relationship among the three attitude components emerges. In these two largest groups, a reasonable to good cognitive basis combines with negative or neutral affective responses and behaviour intentions. These results clarify that with respect to a complex subject such as modern biotechnology, each of the attitude components has its unique contribution to the overall attitude.

\footnotetext{
One of the starting-points of our study was Pardo's argument about the necessity to include a broad range of dimensions in 'modern biotechnology' and its implications, e.g. predictive medicine, genetically modified food and cloning. All these dimensions are important in showing what attitudes towards biotechnology bring about (Pardo et al.,
} 
2002). We tried to cover most of these relevant dimensions in our conceptualisation of attitude towards biotechnology. However, the results of the study by Verdurne and Viaene (2003) on consumer beliefs and attitude towards GM-foods are rather similar to our four clusters. This seems to imply that the public seems to react with similar attitudinal patterns when GM-foods are considered, compared to when a broad range of biotech applications are considered.

We have stated that research on attitudes towards modern biotechnology is important given its expected impact on society. Citizens must be capable to make informed decisions about issues affecting their own lives in the near future. They also should have the opportunity to participate in decision-making processes based on a basic level of understanding socially relevant developments in this field of science. In the light of these scientific literacy goals, education is an important factor. Detailed information on what an attitude towards modern biotechnology entails may serve as a basis for designing good quality education. Our study has clearly shown that the way students think, feel and intent to act with biotechnology is a complex issue.

\section{Future research}

The isolation of a person actual attitude is rather tricky since that person's attitude is always incomplete and in a state of evolution, especially when they deal with extremely complex subjects such as biotechnology is (Campbell et al., 1976; Pardo et al., 2002). This has always been a problem for measuring a complex construct as attitude is. For this reason it is important to replicate the present study in a large and truly random sample of 
Dutch secondary school students. Furthermore, a replication in a sample drawn from the general public would improve the possibility of generalization even more. In such a sample, it would also be possible to examine the validity of the questionnaire, for example by including actual behavioural measures.

\begin{abstract}
A second line of future research concerns the research question on how attitudes patterns towards biotechnology can be explained. General scientific interest may play a role, as well as beliefs regarding science and technology, but also moral beliefs may explain why students hold certain attitudes (Schibeci \& Riley, 1986; Osborne et al., 2003). A number of studies have found several background factors which influence the attitudes people hold (Atwater \& Simpson, 1984; Ajzen \& Fishbein, 2000). Important background factors are personal characteristics, such as religious background, ethnicity, educational level and gender. It is interesting to examine whether group differences emerge in the concept of attitude as defined in our present study.
\end{abstract}

\title{
Implications for science teaching and communication
}

Although limitations have to be taken into account, the findings of this study highlight issues that may have to be considered by curriculum planners and science teachers who wish to incorporate scientific literacy into science curricula. When educating students about modern biotechnology and its implications, one has to keep in mind that students hold different starting points when considering modern biotechnology. Not only should science education focus on knowledge and understanding, but also on the affective side of biotechnology. This change in emphasis might help students to create a more balanced 
attitude towards biotechnology. These findings should be taken into account in the development of educational programmes for secondary school students on informed decision-making towards modern biotechnology.

\section{References}

Ajzen, I. (2001). Nature and operation of attitudes. Annual Review of Psychology, 52, $27-$ 58.

Ajzen, I. \& Fishbein, M. (2000). Attitudes and the attitude-behavior relation: Reasoned and automatic processes, In W. Stroebe \& M. Hewstone. (Eds.), European Review of Social Psychology, pp. 1-33. Chichester: John Wiley \& Sons.

Armitage, C. J. \& Conner, M. (2001). Efficacy of the theory of planned behaviour: A meta-analytic review. British Journal of Social Psychology, 40(4), 471-499.

Atwater, M. \& Simpson, R. (1984). Cognitive and affective variables affect black freshmen in science and engineering at a predominantly white university. School Science and Mathematics, 84, 100-112.

Balas, A. K. \& Hariharan, J. (1998). Cloning: What are their attitudes? A report on the general attitudes of a sample of Midwestern citizens. Paper presented at the National Association for Research in Science Teaching, San Diego, CA.

Becker, K. H. \& Maunsaiyat, S. (2002). Thai students' attitudes and concepts of technology. Journal of Technology Education, 13(2), 6-20.

Bingle, W. H. \& Gaskell, P. J. (1994). Scientific literacy for decision making and the social construction of scientific knowledge. Science Education, 78, 185-201. 
Breckler, S. J. (1984). Empirical validation of affect, behaviour and cognition as distinct components of attitude. Journal of Personality and Social Psychology, 47, 11911205.

Campbell, A., Converse, P. E., Miller, W. E., \& Stokes, D. E. (1976). Science and technology: A comparative study of the European Union, the United States, Japan, and Canada. Chicago: The University of Chicago Press.

Centre for Consumer \& Biotechnology. (2002) Publieksonderzoek genomics; Onderzoeksverslag [Public survey genomics; Survey report]. The Hague: Centre for Consumer \& Biotechnology.

Dawson, V. \& Schibeci, R. (2003a). Western Australian school students' understanding of biotechnology. International Journal of Science Education, 25(1), 57 - 69.

Dawson, V. \& Schibeci, R. (2003b). Western Australian high school students' attitudes towards biotechnology processes. Journal of Biological Education, 38(1), 7-12.

Driver, R., Leach, J., Millar, R., \& Scott, P. (1996). Young people's images of science. Buckingham: Open University Press.

Eagly, A. H. \& Chaiken, S. (1993). The psychology of attitudes. New York: Harcourt College Publishers.

European Commission. (2001). Eurobarometer 55.2 - Europeans, science and technology [online], from http://europa.eu.int/comm/public_opinion (consulted 2003).

European Commission. (2006). Public opinion analysis - Eurobarometer [online], from http://europa.eu.int/comm/public_opinion/index_en.htm 
Gunter, B., Kinderlerer, J., \& Beyleveld, D. (1998). Teenagers and biotechnology: a survey of understanding and opinion in Britain. Studies in Science Education, 32, $81-112$.

Heijs, W. J. M., Midden, C. J. H., \& Drabbe, R. A. J. (1993). Biotechnologie; houdingen en achtergronden [Biotechnology; attitudes and influencing factors]. Eindhoven: Eindhoven University of Technology.

Hill, R., Stannistreet, M., O’Sullivan, H., \& Boyes, E. (1999). Genetic engineering of animals for medical research: Students' views. School Science Review, 80, 23-30.

Human Genetics Commission. (2000) Public attitudes to human genetic information (Survey). London: Human Genetics Commission.

Katz, D. \& Stotland, E. (1959). A preliminary statement to a theory of attitude structure and change, In S. Koch (Ed.), Psychology: A Study of a Science, Vol. 3, pp. 423475. New York: McGraw-Hill.

Kirkpatrick, G., Orvis, K., \& Pittendrigh, B. (2002). GAME: A teaching model for biotechnology. Journal of Biological Education, 37(1), 31-35.

Miller, J. D. (1998). The measurement of civic scientific literacy. Public Understanding of Science, 7(3), 203-223.

Osborne, J., Simon, S., \& Collins, S. (2003). Attitudes towards science: A review of the literature and its implications. International Journal of Science Education, 25(9), 1049-1079.

Pardo, R. \& Calvo, F. (2002). Attitudes toward science among the European public: A methodological analysis. Public Understanding of Science, 11(2), 155-195. 
Pardo, R. \& Calvo, F. (2004). The cognitive dimension of public perceptions of science: Methodological issues. Public Understanding of Science, 13(3), 203-227.

Pardo, R., Midden, C., \& Miller, J. (2002). Attitudes toward biotechnology in the European Union. Journal of Biotechnology, 98(1), 9-24.

Princeton Survey Research Associates. (2002) Public awareness and attitudes about reproductive genetic technology (survey). Washington: The Genetics and Public Policy Center.

Rosenberg, M. J. \& Hovland, C. I. (1960). Cognitive, affective and behavioural components of attitudes, In C. I. Hovland \& M. J. Rosenberg (Eds.), Attitude organisation and change: An analysis of consistency among attitude components, pp. 1-14. New Haven, CT: Yale University Press.

Sadler, T. D. \& Zeidler, D. L. (2004). The morality of socioscientific issues: Construal and resolution of genetic engineering dilemmas. Science Education, 88, 4-27.

Schibeci, R. A. \& Riley, J. P. (1986). Influence of students' background and perceptions on science attitudes and achievement. Journal of Research in Science Teaching, $23,177-187$.

Tesser, A. \& Shaffer, D. (1990). Attitudes and attitude change. Annual Review of Psychology, 41, 479-523.

Verdurme, A. \& Viaene, J. (2003). Consumer beliefs and attitude towards genetically modified food: Basis for segmentation and implications for communication. Agribusiness, 19(1), 91-113. 
Weinburgh, M. \& Engelhard, G. (1994). Gender, prior academic performance and beliefs as predictors of attitudes toward biology laboratory experiences. School Science and Mathematics, 94, 118-123.

Zacharia, Z. (2003). Beliefs, attitudes, and intentions of science teachers regarding the educational use of computer simulations and inquiry-based experiments in physics. Journal of Research in Science Teaching, 40(8), 792-823.

Zeidler, D. L. \& Keefer, M. (2003). The role of moral reasoning and the status of socioscientific issues in science education: Philosophical, psychological and pedagogical considerations, In D. L. Zeidler (Ed.), The role of moral reasoning on socioscientific issues and discourse in science education, pp. 7-38. Dordrecht: Kluwer Academic Press. 
Table 1. Attitude factors with scale name, description, typical items, reliability and descriptive values, based on principal component analyses

\begin{tabular}{|c|c|c|c|c|c|}
\hline $\begin{array}{l}\text { Attitude } \\
\text { components }\end{array}$ & $\begin{array}{l}\text { Attitude } \\
\text { factors }\end{array}$ & Description & Typical item & $\begin{array}{l}\text { Cronbach's } \\
\text { alpha } \\
\text { (No. of } \\
\text { items) }\end{array}$ & $\begin{array}{l}\text { Mean } \\
\text { (SD) }\end{array}$ \\
\hline \multirow[t]{3}{*}{$\begin{array}{l}\text { Cognitive } \\
\text { component }\end{array}$} & $\begin{array}{l}\text { Biology and }{ }^{1} \\
\text { genetics }\end{array}$ & $\begin{array}{l}\text { Knowledge of biology } \\
\text { and genetics }\end{array}$ & $\begin{array}{l}\text { DNA contains the information } \\
\text { for all you hereditary factors. }\end{array}$ & $\begin{array}{l}0.63 \\
(\mathrm{n}=9)\end{array}$ & $\begin{array}{l}7.10 \\
(1.8)\end{array}$ \\
\hline & Biotech $^{1}$ & $\begin{array}{l}\text { Knowledge of biotech } \\
\text { applications }\end{array}$ & $\begin{array}{l}\text { Normal tomatoes have, in } \\
\text { contrast to GM tomatoes, no } \\
\text { genes. }\end{array}$ & $\begin{array}{l}0.71 \\
(\mathrm{n}=17)\end{array}$ & $\begin{array}{l}13.80 \\
(1.8)\end{array}$ \\
\hline & Beliefs & $\begin{array}{l}\text { Evaluative knowledge of } \\
\text { biotech / beliefs about } \\
\text { biotech }\end{array}$ & $\begin{array}{l}\text { I think genomics can solve food } \\
\text { problems in the third world }\end{array}$ & $\begin{array}{l}0.70 \\
(\mathrm{n}=5)\end{array}$ & $\begin{array}{l}3.09 \\
(0.64)\end{array}$ \\
\hline \multirow[t]{3}{*}{$\begin{array}{l}\text { Affective } \\
\text { component }\end{array}$} & Basic emotion & Basic emotional reactions & $\begin{array}{l}\text { Genetic modification (GM) is } \\
\text { bad. }\end{array}$ & $\begin{array}{l}0.78 \\
(\mathrm{n}=13)\end{array}$ & $\begin{array}{l}3.00 \\
(0.58)\end{array}$ \\
\hline & Unavoidable & $\begin{array}{l}\text { Feelings of biotech being } \\
\text { unavoidable }\end{array}$ & $\begin{array}{l}\text { Biotechnology is absolutely } \\
\text { necessary. }\end{array}$ & $\begin{array}{l}0.76 \\
(\mathrm{n}=9)\end{array}$ & $\begin{array}{l}3.12 \\
(0.62)\end{array}$ \\
\hline & Worries & Worries about biotech & $\begin{array}{l}\text { How many worries do you have } \\
\text { about genetic research? }\end{array}$ & $\begin{array}{l}0.79 \\
(\mathrm{n}=5)\end{array}$ & $\begin{array}{l}2.97 \\
(0.79)\end{array}$ \\
\hline \multirow[t]{3}{*}{$\begin{array}{l}\text { Behavioural } \\
\text { component }\end{array}$} & Own intentions & $\begin{array}{l}\text { Consuming intentions; } \\
\text { own interest }\end{array}$ & $\begin{array}{l}\text { I would eat GM food if it was } \\
\text { cheaper than normal food. }\end{array}$ & $\begin{array}{l}0.78 \\
(\mathrm{n}=5)\end{array}$ & $\begin{array}{l}3.09 \\
(0.82)\end{array}$ \\
\hline & $\begin{array}{l}\text { Medical } \\
\text { intentions }\end{array}$ & Medical intentions & $\begin{array}{l}\text { Would you take a genetic test } \\
\text { during your pregnancy? }\end{array}$ & $\begin{array}{l}0.74 \\
(n=4)\end{array}$ & $\begin{array}{l}3.10 \\
(0.83)\end{array}$ \\
\hline & $\begin{array}{l}\text { Critical } \\
\text { intentions }\end{array}$ & $\begin{array}{l}\text { Consuming intentions; } \\
\text { critical conditions }\end{array}$ & $\begin{array}{l}\text { I would buy GM food if it were } \\
\text { grown more environment- } \\
\text { friendly than normal food. }\end{array}$ & $\begin{array}{l}0.74 \\
(\mathrm{n}=3)\end{array}$ & $\begin{array}{l}3.60 \\
(0.90)\end{array}$ \\
\hline
\end{tabular}

\footnotetext{
${ }^{1}$ Bivariate data.
} 


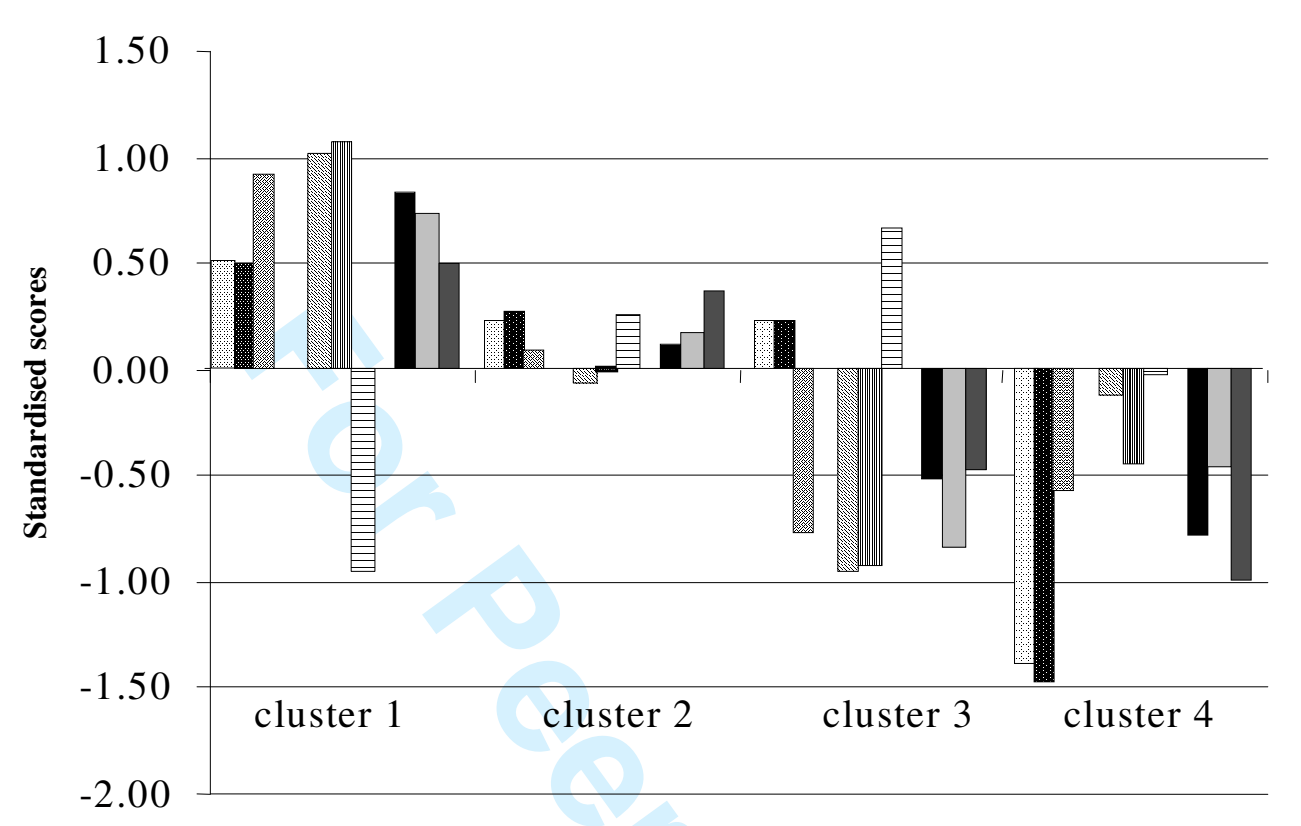

\section{Cognitive} factors

$\square$ biology\& genetics

ㅍil biotechn.

beliefs about biotech

\section{Affective} factors basic emotion unavoidable 国 worries*

\section{Behavioural} intentions

awn intent. $\square$ medical intent. $\square$ critical intent.

Figure 1. Results of k-means cluster analysis of 574 secondary school students' attitudes towards modern biotechnology, using a user-defined cluster number of four.

Cluster 1: confident supporter-cluster $(n=130)$; cluster 2: not sure-cluster $(n=239)$; cluster 3 : concerned sceptic-cluster $(n=105)$; cluster 4: not for me-cluster $(n=100)$. Scores on the different factors of the three main attitudinal components are standardised values.

*Negative score on ' worries-factor' indicates fewer worries about modern biotechnology. 